\title{
Influence of Gas Temperature and Heat Treatment on Microstructure and Properties of Cold Sprayed Commercially Pure Titanium
}

\author{
Magdi F Morks, Saden H Zahiri, Xiao-Bo Chen, Stefan Gulizia, Alejandro Vargas-Uscategui, and Ivan S Cole
}

\author{
Submitted: 15 August 2021 / Revised: 18 November 2021 / Accepted: 11 December 2021 / Published online: 8 February 2022
}

\begin{abstract}
Diffusion of oxygen and nitrogen in the cold sprayed commercially pure Ti (CS CP Ti) deposits profoundly impacts their mechanical properties. One plausible approach to additively manufacture a malleable (wrought) and high-density Ti is optimizing CS deposition parameters considering a reduction in porosity for the following heat treatment. Herein, we examined porosity, bulk density, and hardness characteristics of CS CP Ti deposits produced at varying processing gas temperatures $\left(700,800\right.$, and $\left.900^{\circ} \mathrm{C}\right)$, which significantly influences the interactions of $\mathrm{CP}$ Ti with oxygen and nitrogen. Post-processing heat treatments at 800,900 , and $1000^{\circ} \mathrm{C}$ were performed in a high vacuum furnace, respectively, which diminished splat boundaries and submicron pores with increasing grain size. SEM images revealed that CS CP Ti had a dense microstructure with low porosity. According to LECO research, low spraying temperatures (i.e. $700^{\circ} \mathrm{C}$ ) maintained oxygen and nitrogen levels in the CS CP Ti deposits at the same level as the stock powders. The bulk density of CS CP Ti produced at $900{ }^{\circ} \mathrm{C}$ matched that of wrought $\mathrm{CP}$ Ti metal. In addition, to improve the mechanical properties of CS CP Ti deposits, we looked at the link between CS conditions and heat treatment.
\end{abstract}

Keywords cold spray, density, gas temperature, hardness, heat treatment, oxygen and nitrogen, porosity, titanium

\section{Introduction}

Global industrial community relies on titanium (Ti) and its alloys for aerospace, automotive, defense, mining, oil and gas, and biomedical applications (Ref 1-5). Production of low-cost and high-performance Ti parts is crucial. Manufacturing Ti parts from wrought materials are costly, mainly due to high machining costs and unusable Ti-waste. Recently, direct fabrication technologies such as cold gas dynamic spray (Ref 6) provide great potential for rapid manufacturing of near net shape when the spraying efficiency exceeds $95 \%$. In a typical cold spray (CS) process, stock powders $(5-50 \mu \mathrm{m}$ in diameter) are accelerated to a velocity range of $600-1200 \mathrm{~m} / \mathrm{s}$ by injection into a supersonic gas jet generated by expanding a preheated and pressurized gas through a converging-diverging De Laval type nozzle. Upon impact, the accelerated powders undergo significant deformation and create a bond with the substrate. The particles' continuous impact and strain create

Magdi F Morks, School of Engineering, RMIT University, Melbourne, VIC 3000, Australia; and CSIRO, Manufacturing, Bag 33 Gate 3, Normanby Rd, Clayton, VIC 3168, Australia; Saden H Zahiri, Stefan Gulizia, and Alejandro Vargas-Uscategui, CSIRO, Manufacturing, Bag 33 Gate 3, Normanby Rd, Clayton, VIC 3168, Australia; and Xiao-Bo Chen and Ivan S Cole, School of Engineering, RMIT University, Melbourne, VIC 3000, Australia. Contact e-mails: magdimorks@gmail.com magdi.hanna@rmit.edu.au. metallurgical bonds with the deposited material, resulting in a uniform deposit with porosity and high bond strength (Ref 7-9). The main differences between CS and thermal spray processes are gas temperature and particle velocity. CS utilizes high particle velocities (particles kinetic energy) instead of melting to form coatings, which has many advantages. Although the maximum gas temperature for the CS process is $1000^{\circ} \mathrm{C}$, the temperature of the accelerated particles is always below the melting point. In the CS process, the term cold refers to the state of particles during spraying (Ref 10).

The quality of CS CP Ti depositions depends on the types of powder and substrate and various processing parameters, such as gas pressure and type, processing gas temperature, standoff distance, and particle velocity (Ref 11-15). Extensive research on CS CP Ti coatings and deposits found low mechanical properties, attributed mainly to porosity, oxygen content, residual stress, and weak interfacial bonding at grain boundaries (Ref 16-18). Some studies (Ref 11, 19, 20) looked at the effect of propelling gas temperature and shot-peening particles on the properties of CS materials, and they found a decrease in porosity and enhancement of mechanical properties as the gas temperature increased. Other studies claimed that increasing the gas temperature promoted the deposition efficiency and sequential growth rate of CS CP Ti (Ref 21, 22).

The gas temperature and pressure influence particle velocity during deposition, which rises as the gas temperature increases (Ref 12). The gas' velocity is a function of temperature and density as described by the following gas dynamic equation:

$v_{r m s}=\sqrt{\frac{3 R T}{M_{m}}}$ 
where $v_{\text {rms }}$ is the root-mean-square of the gas velocity, $M_{m}$ is the gas molar mass in kilograms per mole, $R$ is the molar gas constant, and $T$ is the temperature in Kelvin.

Thus, the increase in gas temperature will consequently increase gas velocity (Ref 23). Also, using a low-density gas like helium will impact the particle velocity and the properties of CS materials (Ref 24). Gas temperature (GT) and pressure (GP) are two critical parameters that directly impact the particle velocity (Ref 12).

Many studies ( $\operatorname{Ref} 12,13,21,25,26)$ have reported the effects of GT and feedstock powder on the properties of CS materials using a gas-pressure range of 2.5-5 MPa. However, $\mathrm{CS}$ at high pressure $(6 \mathrm{MPa})$ has yet to be reported, owing to the gas-pressure limitations of the available CS systems. Significant efforts have been undertaken to build a high-gas pressure CS system that allows spraying at high gas pressure (Ref 27). The relationship between propelling gas temperature and pressure and the properties of $\mathrm{CS} \mathrm{CP} \mathrm{Ti}$ is still unknown. For example, there is a lack of data on the characteristics of CS $\mathrm{CP}$ Ti when sprayed at high gas pressures, such as $6 \mathrm{MPa}$, and different gas temperatures. A recent study (Ref 28) on the influence of standoff distance (SoD) showed that increasing SoD from 30 to $70 \mathrm{~mm}$ reduced porosity and enhanced hardness properties of CS Ti-6Al-4V coatings, mainly due to the elimination of shockwave influence.

Post-heat treatment for CS components does not eliminate the porosity but promotes the microstructure and dissipates the boundaries between particles (Ref 29-32). Other studies (Ref 33-35) on laser post-treatment of CS CP Ti coatings and components showed enhanced microstructure and corrosion properties. Blose et al. (Ref 2) studied the mechanical properties (ultimate tensile strength, yield strength, elastic modulus, elongation at break, and reduction in area) for assprayed, heat-treated, and hot isostatic pressed (HIP) CS Ti$6 \mathrm{Al}-4 \mathrm{~V}$ coatings, respectively. According to this study findings, the as-sprayed coating was brittle and mechanically weak. Heat treating increases elasticity, and HIP'ing significantly improved the as-sprayed material's mechanical properties that were comparative or superior to those of wrought metal.

This article investigates the effects of propelling gas temperature and heat treatment on microstructure, hardness, bulk density, diffusion of oxygen and nitrogen, and porosity of CS CP Ti deposits. A set of CS parameters, such as using a maximum gas pressure of $6 \mathrm{MPa}$ and a standoff distance (SoD) of $70 \mathrm{~mm}$, was utilized to increase particle kinetic energy and decrease porosity. Using maximum GP and optimizing GT will work in tandem to reduce porosity and oxygen and nitrogen diffusion during spraying and increase the bulk density of CS CP Ti deposits.

\section{Experimental procedures}

\subsection{Materials}

In this study, CP Ti (grade 2) powders supplied by Osaka Titanium Technologies (Japan) were used as feedstock. The chemical composition of the provided powders was $99.8 \% \mathrm{Ti}$, $0.2 \%$ chloride, $0.02 \%$ nickel, $0.02 \%$ iron, $0.11 \%$ oxygen, and $0.01 \%$ nitrogen, as determined by ICP-OES and LECO instruments. A scanning electron micrograph of the supplied $\mathrm{CP} \mathrm{Ti}$ powder and a particle size distribution analysis are shown in Fig. 1. The vast majority of particles are fully spherical, though some have an oval shape. Saturn DigiSizer II was employed to measure the size distribution of Ti powders. The apparatus captures the scattering laser-light pattern from the samples using a CCD light detector. CCD detector with over three million detector elements enables the entirely automated Saturn DigiSizer II to capture a high-resolution digital representation of the pattern formed by laser light scattered from a sample powder. The powders have nominal particle sizes of 15 to $45 \mu \mathrm{m}$ (mean $28 \mu \mathrm{m}$ ). An aluminum plate with dimensions of $200 \times 100 \times 6 \mathrm{~mm}^{3}$ served as substrate. Before CS deposition, the substrate surface was grit-blasted with $\mathrm{Al}_{2} \mathrm{O}_{3}$, cleaned with compressed air, and washed with ethanol.

\subsection{CS Process}

A 5/10-6/11 CS system from Impact Innovations $\mathrm{GmbH}$ (Germany) was used to fabricate Ti flat deposits on aluminum plates. The CS system consists of a spray gun, powder feeder, power control unit, and cooling water system. The CS system can achieve a maximum gas pressure of $6 \mathrm{MPa}$ and an operating gas temperature of $1000^{\circ} \mathrm{C}$, using a heating power of $40 \mathrm{~kW}$. The spray gun had a water-cooled tungsten carbide nozzle (OUT1-WC) termed a De Laval nozzle, which accelerated the propellant gas to reach supersonic speed. The nozzle has a $6.2 \mathrm{~mm}$ outlet diameter with a $2.5 \mathrm{~mm}$ throat diameter located at $22.6 \mathrm{~mm}$ from the inlet (expansion ratio of 6.2). The inlet diameter was $12.8 \mathrm{~mm}$, and the total length was $160 \mathrm{~mm}$. The nozzle was positioned $162 \mathrm{~mm}$ away from the particle injector utilizing an expanded stainless-steel pre-chamber provided by the CS system manufacturer to increase feedstock dwell time in the hot gas stream. A robotic system model ABB IRB4600 6-DoF from ABB Switzerland was employed to manipulate the spray gun in front of the substrate. The touchscreen control panel facilitates the spray parameters setting such as gas temperature and pressure, powder feed rate, and gas flow rate. Nitrogen gas was employed to accelerate and carry the feedstock powder. Figure 2 shows a visual image of the experimental setup. Table 1 shows a list of spray parameters used in the current study. The SoD was set at $70 \mathrm{~mm}$.

\subsection{Characterisation}

2.3.1 Morphology. Feedstock powder's morphology and CS CP Ti microstructure were observed using Zeiss Merlinfield emission scanning electron microscopy (FESEM) operated in the In-lens mode via secondary electron (SE) detectors. Olympus GX71 optical microscope was employed to take visual images for the grain structure following the heat treatment. Cross-section specimens of dimensions $20 \mathrm{~mm} \times$ $10 \mathrm{~mm} \times 3 \mathrm{~mm}$ were cut from the as-sprayed coupons and mounted in cold resin, followed by grinding with emery papers (grit range: 240-2000), polishing with diamond paste (15-1 $\mu \mathrm{m})$, and buffed with OPS-colloidal silica $(0.25 \mu \mathrm{m})$. After polishing, the specimens were washed with water and ethanol. Cleaning in an ultrasonic cleaner using ethanol removed any particulates stuck on the surface from polished materials. The observed specimens were mounted on an aluminum stub with double-sided conductive carbon tape. The samples were then iridium coated using a Cressington 208HRD sputter coater. The polished specimens were etched using a Kroll's reagent to reveal the grain microstructure. 

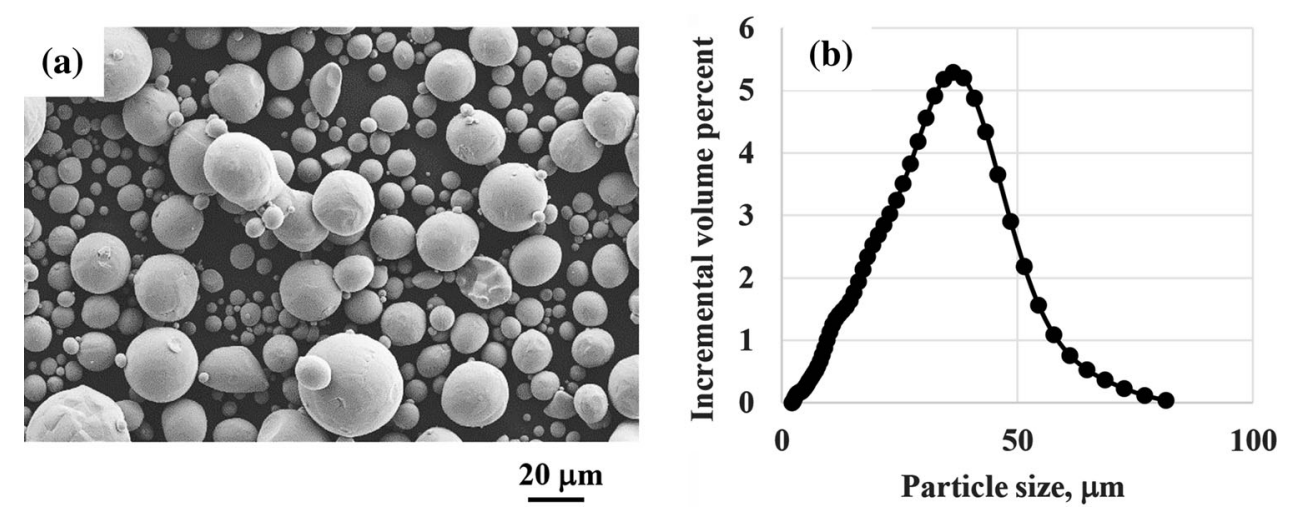

Fig. 1 SEM micrograph (a) and particle size distribution (b) of as-received CP Ti powder
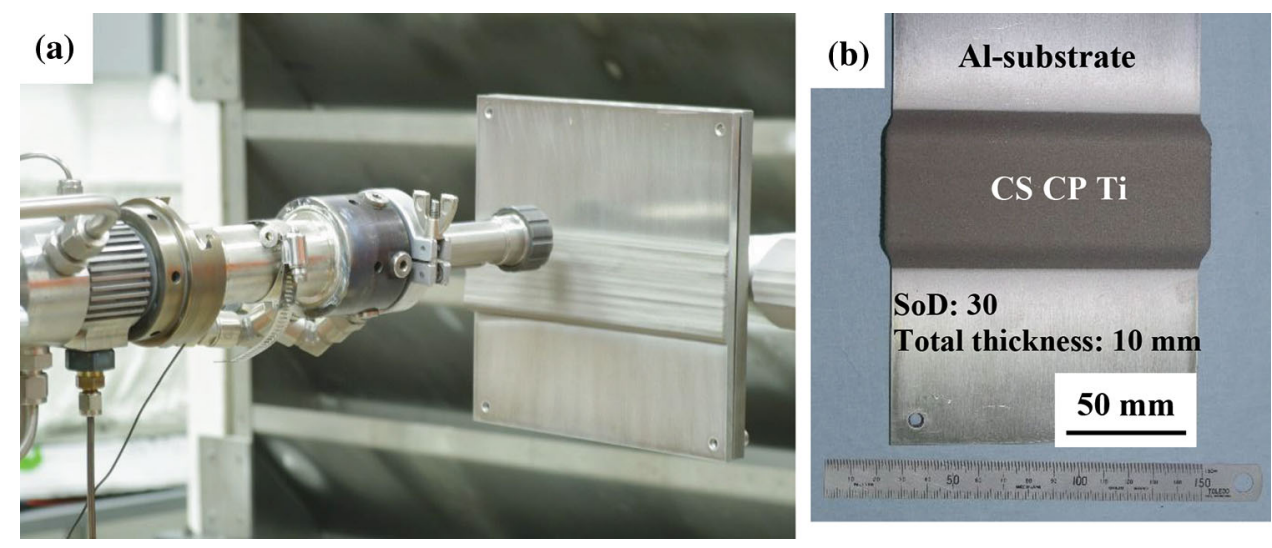

Fig. 2 Experimental set up of: a) Impact Innovations cold spray gun and b) visual image of CS CP Ti flat deposit fabricated on Al substrate

Table 1 List of spray parameters for titanium powders

\begin{tabular}{ll}
\hline Powder & Grade 2 CP Ti \\
\hline Substrate & Aluminum plate \\
Processing \& carrier gas & Nitrogen \\
Gas pressure $(\mathrm{MPa})$ & 6 \\
Gas Temperature $\left({ }^{\circ} \mathrm{C}\right)$ & $700,800,900$ \\
Gas flow rate $(1 / \mathrm{min})$ & 1563 \\
Carrier gas flow rate $(1 / \mathrm{min})$ & 66 \\
Powder feeder rotational speed $(\mathrm{rpm})$ & 2.7 \\
Powder feed rate $(\mathrm{g} / \mathrm{min})$ & $\sim 20$ \\
Standoff Distance $(\mathrm{mm})$ & 70 \\
Traverse speed $(\mathrm{mm} / \mathrm{s})$ & 300 \\
Impact angle $($ degree $)$ & 90 \\
\hline
\end{tabular}

2.3.2 Bulk Density. The total porosity expressed as the sum of open and closed porosity of CS CP Ti samples was measured using Archimedes' principle at ambient temperature. CS CP Ti specimens with dimensions $10 \times 10 \times 5 \mathrm{~mm}^{3}$ were placed inside a metal chamber with a sealed lid under a vacuum of $2.2 \mathrm{kPa}$ for $1 \mathrm{~h}$ to extract any air molecules occupied in the deposit structure's open pores. Water stream allowed to flow inside the chamber and cover the components under vacuum to fill the pores with water for $2 \mathrm{~h}$. The specimens were weighed immediately after being soaked in water for $2 \mathrm{~h}$ (wet weight) to measure the bulk density and apparent porosity. Then, the specimens were weighed while suspended in water using a hook attached to the balance base (suspended weight). Finally, the mass was measured after drying the specimens overnight at $90^{\circ} \mathrm{C}$ in a vacuum oven (dry weight). The volume, density, apparent porosity and open porosity were evaluated in the CS CP Ti deposits using the wet, suspended and dry weight. Each bulk density measurement is the average value of three tests for each specimen.

2.3.3 Heat Treatment. A vacuum furnace model TAV704 was used to heat-treat the CS CP Ti deposits at different temperatures $\left(800,900\right.$ and $\left.1000^{\circ} \mathrm{C}\right)$. The furnace achieves a high vacuum of $5 \times 10^{-3} \mathrm{~Pa}$ using a mechanical and diffusion pump. The display control unit regulates different heating factors such as heating rate, operating temperature, holding time, and cooling rate. All heat-treatment tests were carried out for 1 hour at a rate of $15^{\circ} \mathrm{C} / \mathrm{min}$. The furnace cooling fan was used to cool the CS CP Ti deposits after the heating cycle. The optical and scanning electron microscopy techniques were employed to investigate the changes in microstructure caused by the heat treatment.

2.3.4 Grain-Size Measurement. Heat-treated CS CP Ti specimens were mounted, polished and etched using Kroll's reagent. Olympus GX71 optical microscope was employed to observe grain microstructure changes following the heat treatment at different temperatures. A group of vertical and horizontal lines were drawn on the images with a known magnification scale bar. The number of grain boundaries that intersected the lines was counted. The average grain size was 
then determined by dividing the total lengths of all vertical and horizontal lines by the number of lines-intercepts with grain boundaries, using the following equation:

$i($ averagegrain - size $)=\frac{L_{T}}{P M}$

where $\left(\mathrm{L}_{\mathrm{T}}\right)$ is the total length of all lines, $P$ is the total number of intercepts, and $\mathrm{M}$ is the magnification

$M=\frac{\text { length of scale bar }}{\text { number next to scale bar }}$

2.3.5 Hardness. Buehler Micromet 2100 Series microhardness tester with a Vickers diamond indenter was used to measure CS CP Ti specimens' hardness. The Vickers hardness test used a load of $2.95 \mathrm{~N}$ and a holding time of $10 \mathrm{~s}$. All indentations measurements were performed on polished crosssections of CS CP Ti specimens. For each test, the average value and standard deviation of a set of 15 Vickers hardness measurements were calculated, which covered a surface area of $10 \mathrm{~mm}^{2}$.

\section{Results and Discussion}

\subsection{Microstructure}

Figure 3 shows the scanning electron microscope images of as-deposited cross-sectioned CS CP Ti fabricated at different gas temperatures $\left(700,800\right.$ and $\left.900^{\circ} \mathrm{C}\right)$ and high gas pressure of $6 \mathrm{MPa}$. The low magnification microstructure images revealed that the $\mathrm{CS} \mathrm{CP} \mathrm{Ti}$ deposits were uniform with no visible cracks or big voids. The SEM images showed a reduction of pore quantity and pore size as the gas temperature increased. According to the SEM images, the estimated pore size ranges at $12-30 \mu \mathrm{m}$ for $\mathrm{CS} \mathrm{CP}$ Ti at gas temperature (GT) $700^{\circ} \mathrm{C}, 7-20 \mu \mathrm{m}$ at $\mathrm{GT} 800^{\circ} \mathrm{C}$, and $3-11 \mu \mathrm{m}$ for $\mathrm{CS} \mathrm{CP} \mathrm{Ti}$ fabricated at (GT) $900^{\circ} \mathrm{C}$. The decrease in pore size with increasing gas temperature is primarily due to increased particle deformation. The deformation of particles occurs due to the high compressive stress at the point of impact (Ref 36). The microstructure in Fig. 3-f suggests a high plastic deformation occurred for CS CP Ti particles sprayed at GT $900^{\circ} \mathrm{C}$. The results agree with a previous study by Binder et al. (Ref 11), which revealed that particles are hard to deform when setting the propellant gas at low gas temperature. Fine grains were found around the particle boundaries in the particle/particle regions (Fig. 3d) due to the hardworking during particle deformation (Ref 37). The formation of refined grains is attributed to the dynamic crystallization following the particles' high-strain rate deformation (Ref 37).

The pores morphologies vary from elongated pores to triangular, square and irregular shapes. As the gas temperature increases, the particles's velocity and temperature increase, which enhances the plastic deformation of the impacted particles (Ref 38). Pore shrinkage and pore fraction reduction with gas temperature indicated a high particle deformation rate. Particle boundaries (white lines) are observed at high magnification, as illustrated in Fig. 3(b, d, and f). Particle boundaries usually appear following the particles' plastic deformation. The particle boundaries are net of lines across the microstructure. The large pores, voids and particle boundaries are considered defects that impact the tensile properties of CS CP Ti deposits.

\subsection{Porosity and Bulk Density}

Figure 4 shows the porosity and bulk density as determined by Archimedes' principle. As GT increased from 700 to $900^{\circ} \mathrm{C}$, the porosity decreased from $5.1 \%$ to $1.2 \%$. Furthermore, as the gas temperature increased, the bulk density increased to $4.5 \mathrm{~g} /$ $\mathrm{cm}^{3}$ at GT $900^{\circ} \mathrm{C}$, nearly matching the bulk density of Off-TheShelf (OTS) CP Ti materials $\left(4.5 \mathrm{~g} / \mathrm{cm}^{3}\right)$. The increase in bulk density could be related to the decrease in the volume fraction of porosity as the gas temperature increase (Ref 20, 39). Previous studies (Ref 12, 19, 23, 40) showed that increasing the processing GT increases the rate of acceleration of particles and reduces the critical velocities resulting in enhanced plastic deformation and bonding strength. It was reported by Li et al. (Ref 41) that the critical velocity decreases by increasing the particle temperature, which can be achieved by increasing the dwell time of the particles in the hot gas stream.

The density of CS CP Ti components relies on a set of spray parameters of those the gas temperature and pressure are considered the most influential parameters (Ref 20, 39). These parameters impact the particles' speed and temperature, affecting the plastic deformation after impact on the substrate or other flattened particles. Here the gas pressure was maintained at a maximum value of $6 \mathrm{MPa}$ in all deposition processes. The results show that upon setting the gas pressure at the maximum value (6 MPa), CS CP Ti deposits exhibit a dense structure and low porosity at GT $800^{\circ} \mathrm{C}$. One of the main benefits of reducing the gas temperature and increasing the gas pressure is to minimize brittle oxides and nitrides in the material's structure.

\subsection{Oxygen and Nitrogen Diffusion}

Figure 5 shows LECO analysis of elemental oxygen and nitrogen content in the $\mathrm{CS} \mathrm{CP}$ Ti deposited at different gas temperatures. CS CP Ti deposits fabricated at GT 700 and $800^{\circ} \mathrm{C}$ have oxygen and nitrogen per cent $(\mathrm{O}: 0.14-0.13$ and $\mathrm{N}$ : $0.01-0.02)$ close to the starting powder $(\mathrm{O}: 0.11$ and $\mathrm{N}: 0.01)$. However, oxygen increased by $23 \%$ and nitrogen by 1.5 times as the gas temperature increased from 800 to $900^{\circ} \mathrm{C}$. The presence of elemental oxygen and nitrogen in the CS CP Ti structure is attributed to oxygen and nitrogen diffusion from the processing nitrogen gas $(\mathrm{N})$ and air atmosphere during the substrate's particle impact and deformation. The diffusion of oxygen and nitrogen can promote the oxidation and nitriding of Ti particles in the hot gas stream. Compared with other studies (Ref 6, 42, 43), CS CP Ti deposits showed significantly low oxygen per cent. The LECO analysis suggests increasing the gas temperature from 800 to $900^{\circ} \mathrm{C}$ increased oxygen and nitrogen content to $0.03 \%$. Nitrogen and oxygen rates increase as particles' surface temperature increases by gas-heat transfer, which agrees with the study of Li et al. (Ref 30).

\subsection{Heat Treatment}

Figure 6 shows the SEM micrographs of etched crosssectioned CS CP Ti specimens following heat treatment at 800 and $900^{\circ} \mathrm{C}$ for one hour in the high vacuum furnace. The splat boundaries dissipated following the heat treatment at 800, 900 and $1000^{\circ} \mathrm{C}$. Recrystallization following the heat treatment resulted in the complete disappearance of splat boundaries and eliminated most tiny pores for CS CP $\mathrm{Ti}$ fabricated at gas temperature 800 and $900^{\circ} \mathrm{C}$. The SEM images indicated a change in microstructure due to the gas temperature (GT) and heat treatment (HT). CS CP Ti deposits fabricated at GT $800^{\circ} \mathrm{C}$ 

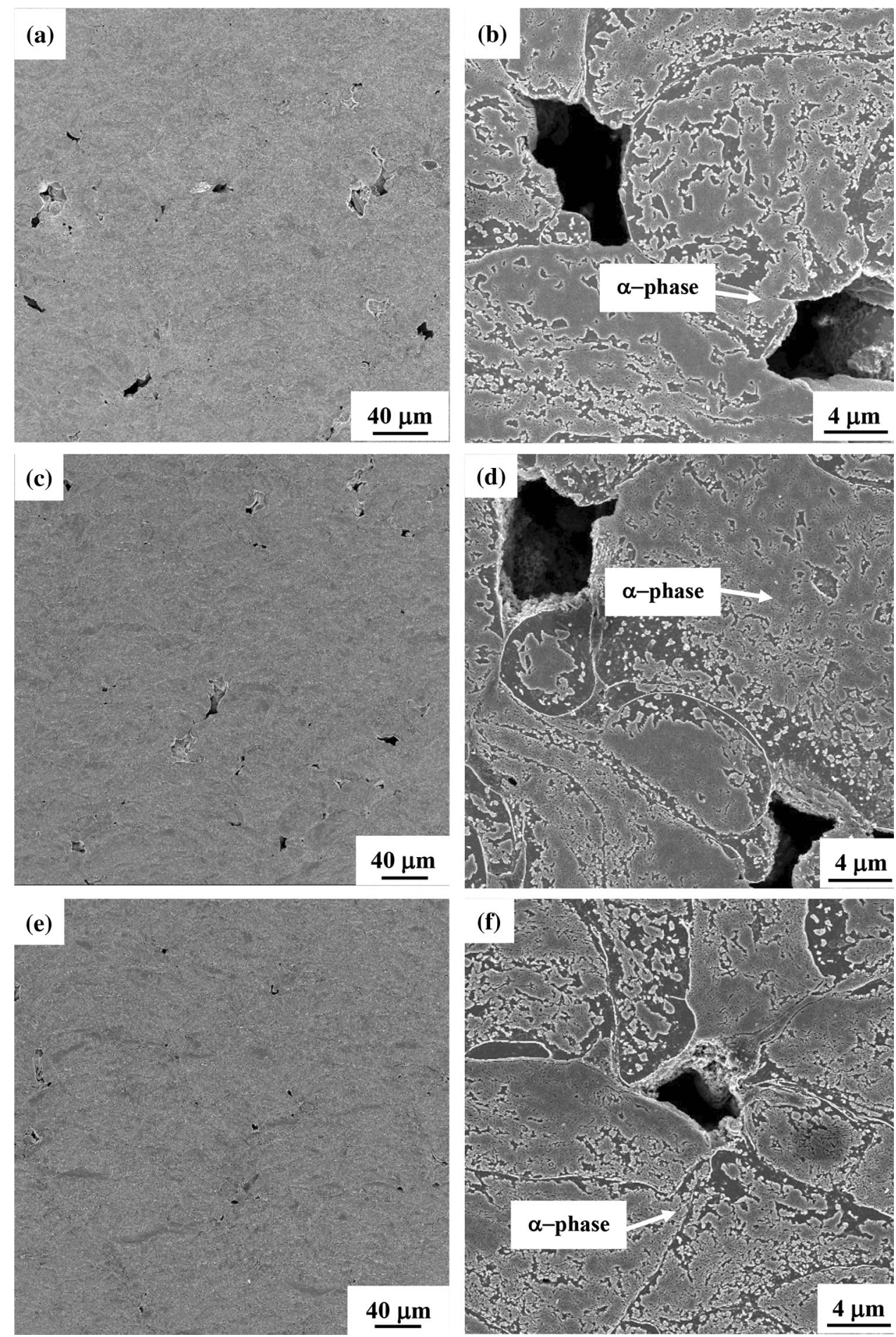

Fig. 3 SEM Micrographs for cross-sectioned CS CP Ti Flat deposits fabricated at different GTs: (a, b) $700^{\circ} \mathrm{C},(\mathrm{c}, \mathrm{d}) 800^{\circ} \mathrm{C}$ and $(\mathrm{e}, \mathrm{f}) 900^{\circ} \mathrm{C}$

and heat-treated at $800^{\circ} \mathrm{C}$ composed of $\alpha$-phase (light) in a round colony. The average size of the colony ranges from 8 to $20 \mu \mathrm{m}$. As the gas temperature increased to $900^{\circ} \mathrm{C}$, the microstructure showed a denser and refined $\alpha$-phase than observed at gas temperature $800^{\circ} \mathrm{C}$ following heat treatment at $800^{\circ} \mathrm{C}$ (Fig. 6 b). The increase in black phases with increasing the heat temperature is probably due to phase transition at elevated temperatures (Fig. 6e and f). The $\alpha-\beta$ transition is expected at extreme heat treatment temperatures of $>900^{\circ} \mathrm{C}$; nevertheless, the higher temperature $\beta$-phase is likely to change to the lower temperature $\alpha$-phase in CS CP Ti following cooling in transus temperature. The phase transitions between $\alpha$ and $\beta$ can result in grain refinement and arrangement.

\subsection{Grain Size and Heat Treatment}

Figure 7 represents the optical microscope images taken for etched cross-sectioned CS CP Ti deposits after heat-treated at different temperatures $\left(800-1000^{\circ} \mathrm{C}\right)$. Analysis of the obtained images demonstrated that the increase in heat treatment 


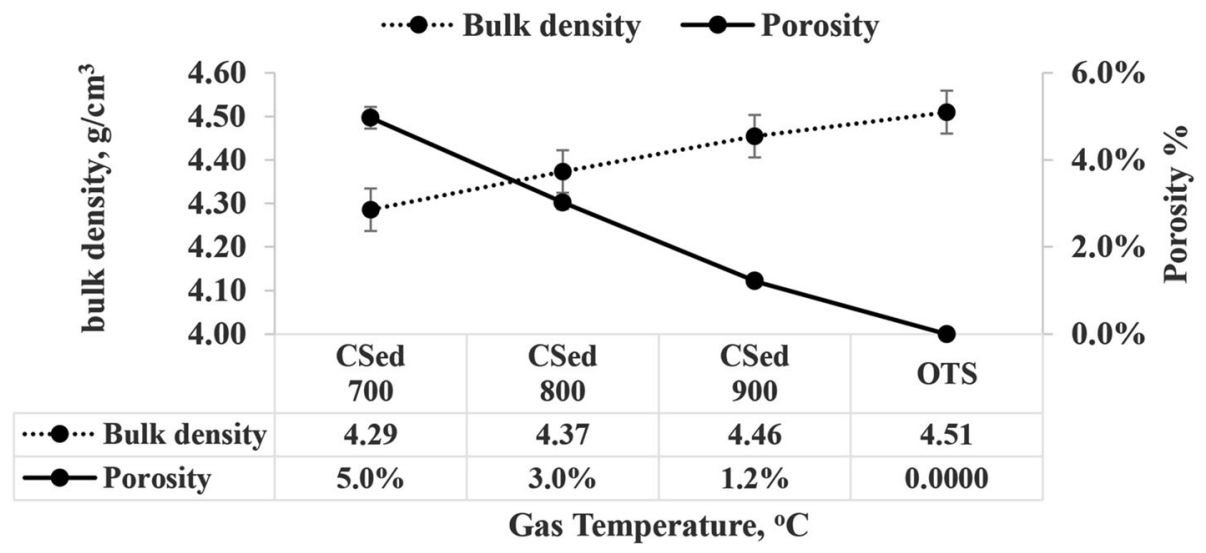

Fig. 4 Bulk density and porosity measurements of off-the-shelf CP Ti (Grade 2) and CS CP Ti deposits fabricated at different GTs

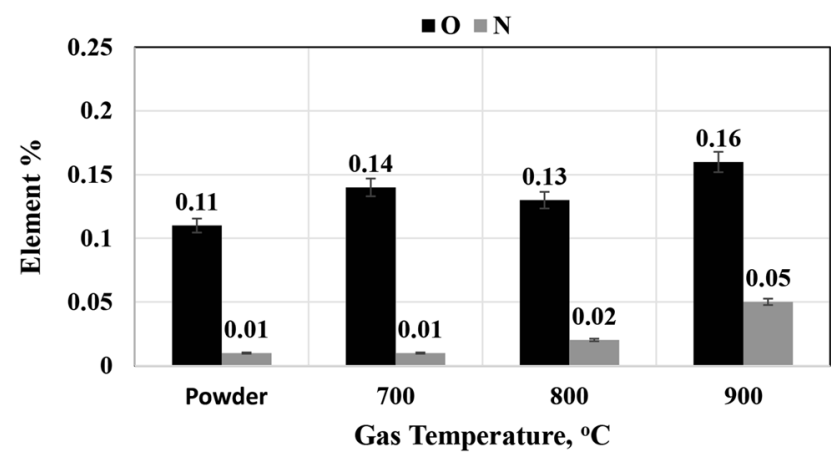

Fig. 5 LECO analysis data for $\mathrm{Ti}$ powder and $\mathrm{CS} \mathrm{CP} \mathrm{Ti}$ at different GTs

temperature increases grains size. At high temperatures (900 and $1000^{\circ} \mathrm{C}$ ), grain expansion is likely due to the disappearance of grain boundaries and re-combined micro grains with the same orientation into a large grain. The images also showed large round-shaped pores $(>20 \mu \mathrm{m})$ in the CS CP Ti structure after heat-treated at $1000^{\circ} \mathrm{C}$ and gas temperature at $800^{\circ} \mathrm{C}$ (Fig. $7 \mathrm{~b}$ and e). The presence of large-size pores indicates that post-heat treatment has no evident impact on vanishing large pores. Also, grain size growth with heat-treatment temperature impacted the pores morphology from sharp-edge to curved corners (Fig. 3).

Figure 8 shows the change in grain size in micron with the heat-treatment temperature. Grain-size measurements (Fig. 8) showed a linear increase of grain size from 13 to $35 \mu \mathrm{m}$ as the temperature increased from 800 to $1000^{\circ} \mathrm{C}$. It has been found that the change in GT has no impact on the grains size growth at different heat-treatment temperatures, as illustrated in Fig. 8.

\subsection{Hardness}

Figure 9 shows the average Vickers hardness indentation measurements versus GT of cross-sectioned CS CP Ti deposits. Hardness slightly increased from $204 \mathrm{HV}(0.3)$ to $214 \mathrm{HV}(0.3)$ as GT increased from $700^{\circ} \mathrm{C}$ to $900^{\circ} \mathrm{C}$, mainly due to increased plastic deformation and thus the strain hardening. Increasing the gas temperature over $800^{\circ} \mathrm{C}$ has no impact on the hardness value. The hardness of as-deposits $\mathrm{CS} \mathrm{CP} \mathrm{Ti} \mathrm{was} \mathrm{27 \%} \mathrm{higher}$ than the off-the-shelf $\mathrm{CP}$ Ti due to the cold work hardening of the CS CP Ti splats during the plastic deformation at high kinetic energy (Ref 44), creating compressive residual stress and improving the hardness and fatigue properties (Ref 45, 46).

Hardness is a complex property related to the extent to which solids resist elastic and plastic deformation (Ref 47). Also, the degree of crystallinity or crystal structure order impacts the hardness of solid materials. The residual stresses, grain boundaries, and porosities are common defects in the asdeposit CS CP Ti structure generated by high-velocity particles' impact. Off-The-Shelf (OTS) material has homogeneous grain size and shape, while CS CP Ti deposits have extremely refined grain structure near the edges of the splat combined with larger grain size in the core of the splat. In addition to this, there is an increased dislocation density in the CS material. Off-the-shelf commercial pure $\mathrm{Ti}$ is more crystalline than $\mathrm{CS} \mathrm{CP} \mathrm{Ti}$ and needs less energy (force/area) to work hardening the grains during the indentation test. As explained above, CS CP suffers from crystal-structural defects, and the grains have more resistance to diamond indentation than OTS CP Ti.

Figure 10 illustrates the change of Vickers hardness of CS $\mathrm{CP}$ Ti with heat treatment temperature. The results indicate that heat-treated CS CP Ti deposits fabricated at gas temperature 800 and $900^{\circ} \mathrm{C}$ showed lower hardness than as-deposited CS CP Ti (Fig. 9). Post-heat treatment decreased the hardness value of CS CP Ti due to the recrystallization happening during the heat-treatment process. At the gas temperature of $800^{\circ} \mathrm{C}$, the hardness values did not change significantly as the heattreatment temperature increased from 800 to $900^{\circ} \mathrm{C}$. However, the hardness increased following the heat treatment at $1000^{\circ} \mathrm{C}$, probably due to the partial phase transition of Ti- from $\alpha$ (hexagonal) to $\beta$ (cubic). At a gas temperature of $900^{\circ} \mathrm{C}$, the hardness value slightly increased with the heat-treatment temperature. Following heat treatment, the CS CP Ti fabricated at a gas temperature of $900^{\circ} \mathrm{C}$ had higher hardness than fabricated at a lower gas temperature of $800^{\circ} \mathrm{C}$ due to higher density and lower porosity.

\section{Conclusions}

CP Ti flat deposits were fabricated via the CS process at a high gas pressure $(6 \mathrm{MPa})$ and different GTs $(700,800$ and $900^{\circ} \mathrm{C}$ ). This research highlights the influence of GT and postheat treatment at 800,900 and $1000^{\circ} \mathrm{C}$ on CS CP Ti deposits' microstructure and properties. The results showed the potential 

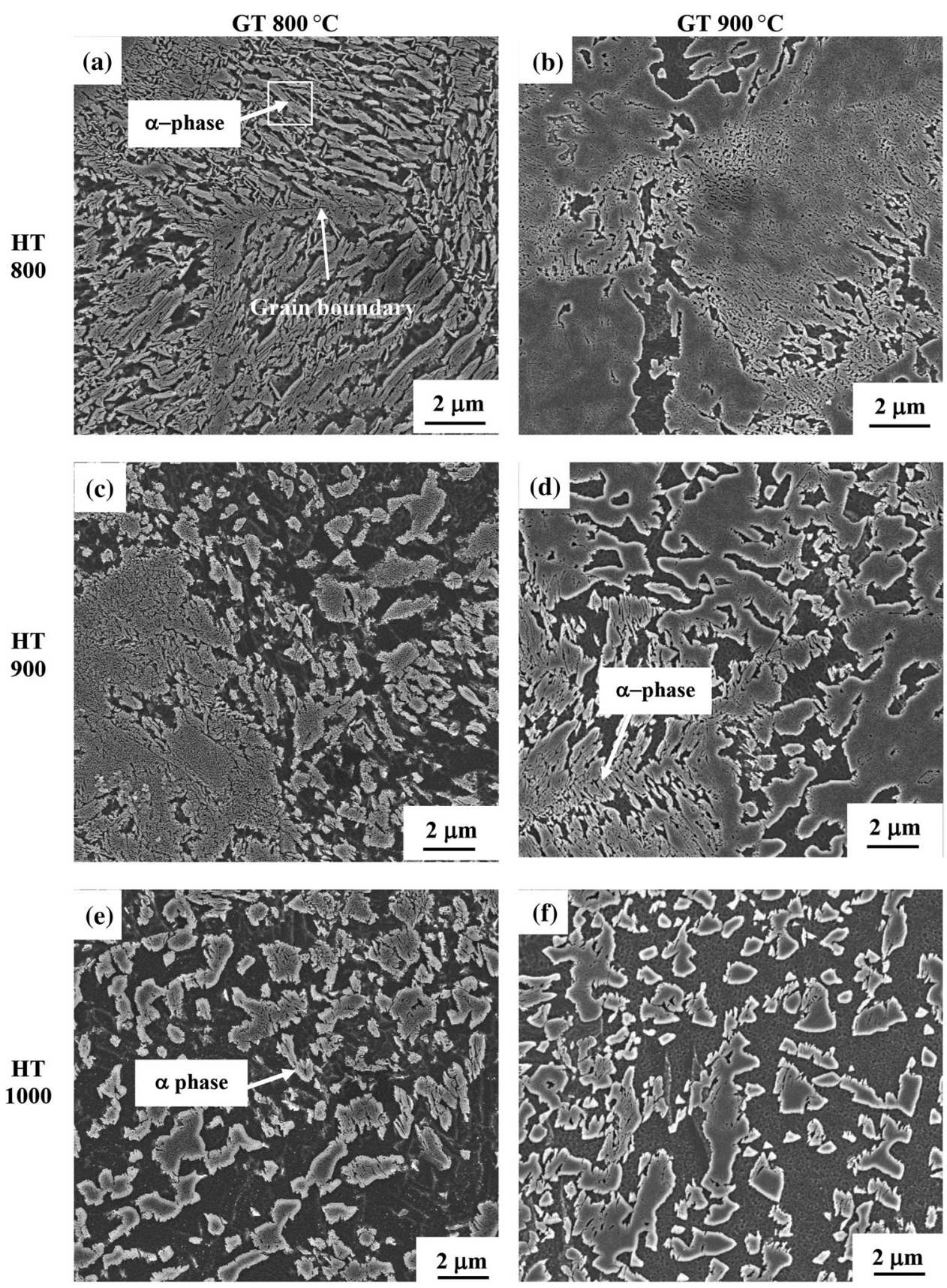

Fig. 6 SEM micrographs of CS CP Ti deposits fabricated at different GTs (800 and $\left.900{ }^{\circ} \mathrm{C}\right)$ and heat-treated at 800,900 and $1000^{\circ} \mathrm{C}$

of fabricating high-performance titanium materials for biomedical, aerospace and defenze applications by optimizing the spray parameters and post-heat treatment. The main results of the current study are summarised as follows:

1. Bulk density increased, and the volume fraction of porosity decreased as the GT increased.

2. The oxygen and nitrogen concentrations of CS CP Ti deposits did not change after spraying at 700 and $800^{\circ} \mathrm{C}$ GTs. However, when the GT increased from 800 to $900^{\circ} \mathrm{C}$, oxygen increased by $23 \%$ and nitrogen increased by 1.5 times.

3. The highest hardness value (214 HV (0.3)) was obtained at GTs of 800 and $900^{\circ} \mathrm{C}$.

4. Heat treatment at 800,900 , and $1000^{\circ} \mathrm{C}$ resulted in the disappearance of splat boundaries and the elimination of most submicron pores in CS CP Ti produced at GT 800 and $900^{\circ} \mathrm{C}$.

5. Increasing the heat-treatment temperature from 800 to $1000^{\circ} \mathrm{C}$ resulted in a linear increase in grain size from 13 to $35 \mu \mathrm{m}$. 

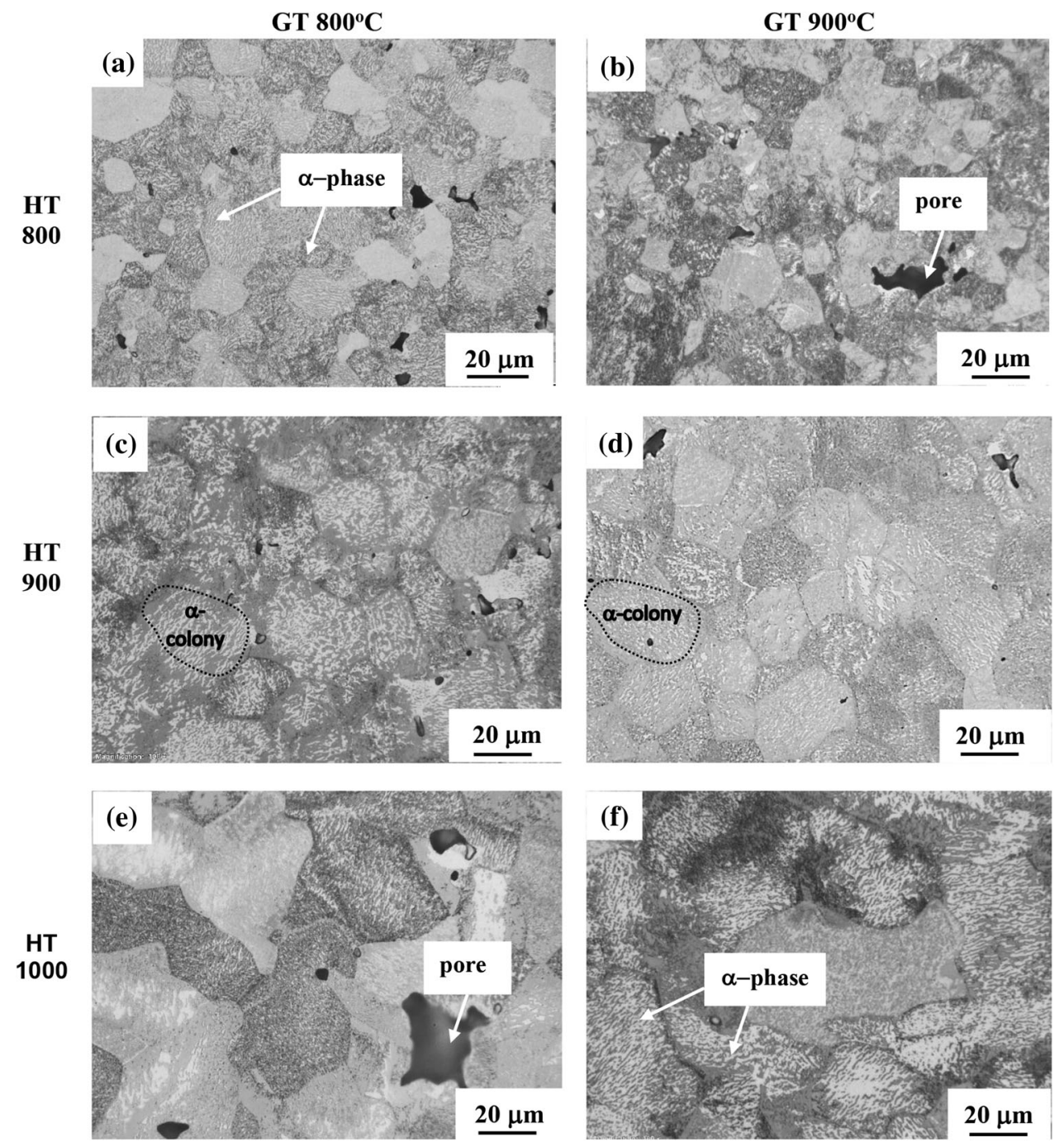

Fig. 7 Optical microscope images showing the grains' growth of polished and etched CS CP Ti fabricated at different GTs $\left(800\right.$ and $\left.900^{\circ} \mathrm{C}\right)$ and heat-treated at $800^{\circ} \mathrm{C}(\mathrm{a}, \mathrm{b}), 900^{\circ} \mathrm{C}(\mathrm{c}, \mathrm{d})$ and $1000^{\circ} \mathrm{C}(\mathrm{e}, \mathrm{f})$

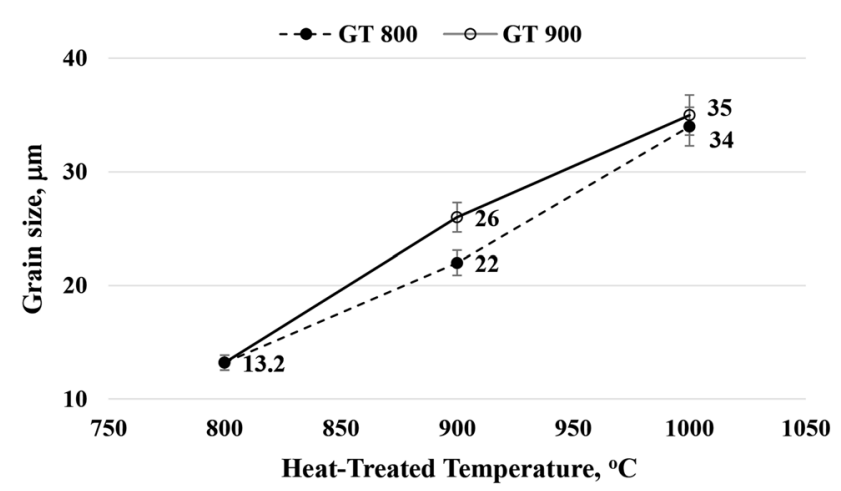

Fig. 8 The change in grain size of CS CP Ti with heat-treatment temperature

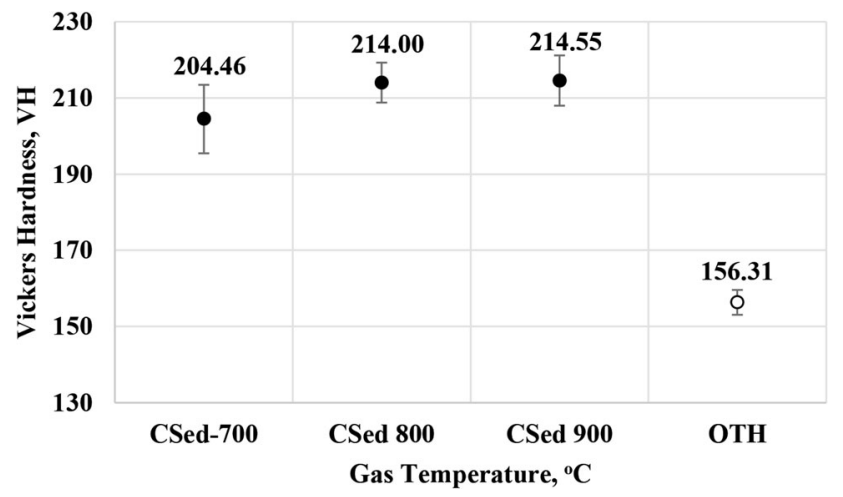

Fig. 9 Vickers hardness of off-the-shelf CP Ti and as-deposited CS CP Ti fabricated at different GTs 


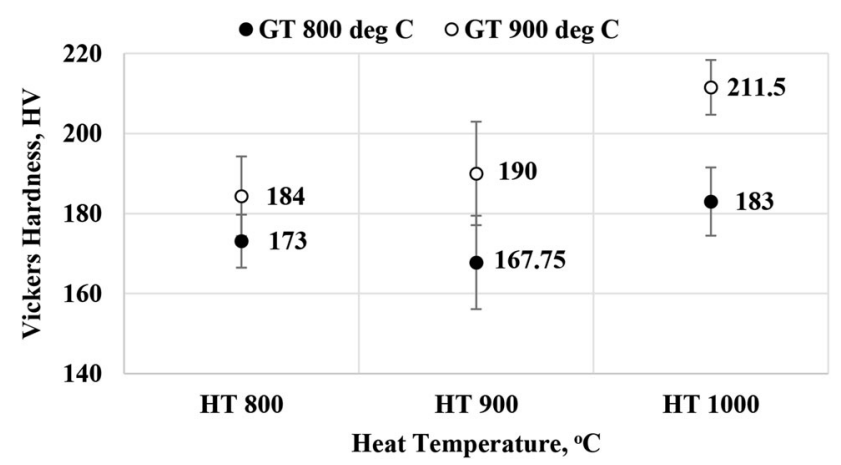

Fig. 10 Vickers hardness of heat-treated CS CP Ti fabricated at different GTs

\section{Acknowledgment}

The authors are grateful to CSIRO's Lab 22 (Clayton, VIC) for providing access to the cold spray laboratory and preparation of $\mathrm{CS}$ CP Ti specimens, RMIT University for characterization techniques, and financial support of the Australian IMCRC Organization.

\section{Funding}

Open Access funding enabled and organized by CAUL and its Member Institutions.

\section{Open Access}

This article is licensed under a Creative Commons Attribution 4.0 International License, which permits use, sharing, adaptation, distribution and reproduction in any medium or format, as long as you give appropriate credit to the original author(s) and the source, provide a link to the Creative Commons licence, and indicate if changes were made. The images or other third party material in this article are included in the article's Creative Commons licence, unless indicated otherwise in a credit line to the material. If material is not included in the article's Creative Commons licence and your intended use is not permitted by statutory regulation or exceeds the permitted use, you will need to obtain permission directly from the copyright holder. To view a copy of this licence, visit http://creativecommons.org/licenses/by/4.0/.

\section{References}

1. R.R. Boyer, An overview on the use of titanium in the aerospace industry, Mater. Sci. Eng. A, 1996, 213, p 103-114

2. R. E. Blose, B. H. Walker, R. M. Walker, S. H. Froes, Met. Powder Rep., 2006, 61 (9), 30-37

3. C. Lee, J. Kim, High Press. Cold Spray 227 (2020)

4. S. Leuders, M. Thöne, A. Riemer, T. Niendorf, T. Tröster and H.A. Richard, Maier, On the mechanical behaviour of titanium alloy TiA16V4 manufactured by selective laser melting: fatigue resistance and crack growth performance, Int. J. Fatigue, 2013, 48, p 300-307

5. A.M.V.N. Cinca, N.G.S.D.I.G. Cano and X.N.J.M. Guilemany, Osteoblastic cell response on high-rough titanium coatings by cold spray, J. Mater. Sci. Mater. Med., 2018, 29(19), p 1-10

6. M. Jahedi, S. Zahiri, S. Gulizia, B. Tiganis, C. Tang and D. Fraser, Direct manufacturing of titanium parts by cold spray, Mater. Sci. Forum, 2009, 618(619), p 505-508

7. G. Bae, S. Kumar, S. Yoon, K. Kang, H. Na, H.J. Kim and C. Lee, Bonding features and associated mechanisms in kinetic sprayed titanium coatings, Acta Mater., 2009, 57(19), p 5654
8. M.V. Vidaller, A. List, F. Gaertner, T. Klassen, S. Dosta and J.M. Guilemany, Single impact bonding of cold sprayed Ti-6Al-4V powders on different substrates, J. Therm. Spray Technol., 2015, 24(4), p 644658

9. R.C. Dykhuizen, M.F. Smith, D.L. Gilmore, R.A. Neiser, X. Jiang and S. Sampath, Impact of high velocity cold spray particles, J. Therm. Spray Technol., 1999, 8(4), p 559-564

10. F. Gärtner, T. Stoltenhoff, T. Schmidt and H. Kreye, The cold spray process and its potential for industrial applications, J. Therm. Spray Technol., 2006, 15(2), p 223-232

11. K. Binder, J. Gottschalk, M. Kollenda, F. Gärtner and T. Klassen, Influence of impact angle and gas temperature on mechanical properties of titanium cold spray deposits, J. Therm. Spray Technol., 2011, 20(12), p 234-242

12. D. Goldbaum, J.M. Shockley, R.R. Chromik, A. Rezaeian, S. Yue, J.G. Legoux and E. Irissou, The effect of deposition conditions on adhesion strength of Ti and Ti6Al4V cold spray splats, J. Therm. Spray Technol., 2012, 21(2), p 288-303

13. V.S. Bhattiprolu, K.W. Johnson, O.C. Ozdemir and G.A. Crawford, Influence of feedstock powder and cold spray processing parameters on microstructure and mechanical properties of Ti-6Al-4V cold spray depositions, Surf. Coat. Technol., 2017, 335, p 1-12

14. W. Wong, E. Irissou, A.N. Ryabinin, J.G. Legoux and S. Yue, Influence of helium and nitrogen gases on the properties of cold gas dynamic sprayed pure titanium coatings, J. Therm. Spray Technol., 2011, 20(12), p 213-226

15. J. Pattison, S. Celotto, A. Khan and W. O'Neill, Standoff distance and bow shock phenomena in the Cold Spray process, Surf. Coat. Technol., 2007, 202(8), p 1443-1454

16. J. Ajaja, D. Goldbaum and R.R. Chromik, Characterisation of Ti cold spray coatings by indentation methods, Acta Astronaut., 2011, 69(1112), p 923-928

17. P.C. King, C. Busch, T. Kittel-Sherri, M. Jahedi and S. Gulizia, Interface melding in cold spray titanium particle impact, Surf. Coat. Technol., 2013, 239, p 191-199

18. W. Wong, P. Vo, E. Irissou, A.N. Ryabinin, J.G. Legoux and S. Yue, Effect of particle morphology and size distribution on cold-sprayed pure titanium coatings, J. Therm. Spray Technol., 2013, 22(7), p 11401153

19. H. Zhou, C. Li, G. Ji, S. Fu, H. Yang, X. Luo, G. Yang and C. Li, Local microstructure inhomogeneity and gas temperature effect in in-situ shot-peening assisted cold-sprayed Ti-6Al-4V coating, J. Alloys Compd., 2018, 766, p 694-704

20. J. Lee, S. Shin, H.J. Kim and C. Lee, Effect of gas temperature on critical velocity and deposition characteristics in kinetic spraying, Appl. Surf. Sci., 2007, 253(7), p 3512-3520

21. C.J. Li and W.Y. Li, Deposition characteristics of titanium coating in cold spraying, Surf. Coat. Technol., 2003, 167(2-3), p 278-283

22. W. Wong, A. Rezaeian, S. Yue, E. Irissou, J. G. Legoux in ITSC (2009)

23. T. Schmidt, F. Gaertner and H. Kreye, New developments in cold spray based on higher gas and particle temperatures, J. Therm. Spray Technol., 2006, 15, p 488-494

24. M. Grujicic, C. Tong, W. S. DeRosset, D. Helfritch, (2003) Flow analysis and nozzle-shape optimisation for the cold-gas dynamic-spray process, Proc. Inst. Mech. Eng. Part B J. Eng. Manuf., 217 (11): 16031613

25. D.L. Gilmore, R.C. Dykhuizen, R.A. Neiser, T.J. Roemer and M.F. Smith, Particle velocity and deposition efficiency in the cold spray process, J. Therm. Spray Technol., 1999, 8(4), p 576-582

26. W.Y. Li, C.J. Li and H. Liao, Significant influence of particle surface oxidation on deposition efficiency, interface microstructure and adhesive strength of cold-sprayed copper coatings, Appl. Surf. Sci., 2010, 256(16), p 4953-4958

27. P. S. Richter, S. G. Ruoff, ASM International. 107 (2016)

28. M.F. Morks, S. Zahiri, X.B. Chen, S. Gulizia and I.S. Cole, Enhancement of the corrosion properties of cold sprayed Ti-6Al-4V coatings on mild steel via silica sealer, Mater. Corros., $2021 \mathrm{https} / / / \mathrm{doi}$. org/10.1002/maco.202112504

29. W.Y. Li, C. Zhang, H. Liao and C. Coddet, Effect of heat treatment on microstructure and mechanical properties of cold sprayed Ti coatings with relatively large powder particles, J. Coat. Technol. Res., 2009, 6(3), p 40-406

30. W.Y. Li, C. Zhang, H.-T. Wang, X.P. Guo, H.L. Liao, C.-J. Li and C. Coddet, Significant influences of metal reactivity and oxide films at 
particle surfaces on coating microstructure in cold spraying, Appl. Surf. Sci., 2007, 253(7), p 3557-3562

31. P. Vo, E. Irissou, J.G. Legoux and S. Yue, Mechanical and microstructural characterisation of cold-sprayed Ti-6Al-4V after heat treatment, J. Therm. Spray Technol., 2013, 22(6), p 954-964

32. Y.Q. Ren, P.C. King, Y.S. Yang, T.Q. Xiao, C. Chu, S. Gulizia and A.B. Murphy, Characterisation of heat treatment-induced pore structure changes in cold-sprayed titanium, Mater. Charact., 2017, 132, p 69-75

33. F. Rubino, A. Astarita, P. Carlone, S. Genna, C. Leone, F.M.C. Minutolo and A. Squillace, Selective laser post-treatment on titanium cold spray coatings, Mater. Manuf. Process., 2016, 31(11), p 15001506

34. A. Astarita, S. Genna, C. Leone, C.M.F. Memola, F. Rubino and A. Squillace, Study of the laser remelting of a cold sprayed titanium layer, Procedia CIRP, 2015, 33, p 452-457

35. T. Marrocco, T. Hussain, D.G. McCartney and P.H. Shipway, Corrosion performance of laser posttreated cold sprayed titanium coatings, J. Therm. Spray Technol., 2011, 20(4), p 909-917

36. A.M. Birt, V.K. Champagne, R.D. Sisson and D. Apelian, Microstructural analysis of cold-sprayed Ti-6Al-4V at the micro-and nano-scale, $J$. Therm. Spray Technol., 2015, 24(7), p 1277-1288

37. Y. Zou, W. Qin, E. Irissou, J.G. Legoux, S. Yue and J.A. Szpunar, Dynamic recrystallisation in the particle/particle interfacial region of cold-sprayed nickel coating: electron backscatter diffraction characterisation, Scr. Mater, 2009, 61(9), p 899-902

38. W.Y. Li, H. Liao, H.T. Wang, C.J. Li, G. Zhang and C. Coddet, Optimal design of a convergent-barrel cold spray nozzle by numerical method, Appl. Surf. Sci., 2006, 253(2), p 708-713
39. N. Cinca, M. Barbosa, S. Dosta and J.M. Guilemany, Study of Ti deposition onto Al alloy by cold gas spraying, Surf. Coat. Technol., 2010, 205(4), p 1096-1102

40. T. Stoltenhoff, H. Kreye and H.J. Richter, An analysis of the cold spray process and its coatings, J. Therm. Spray Technol., 2002, 11(4), p 542-550

41. C.J. Li, W.Y. Li and H. Liao, Examination of the critical velocity for deposition of particles in cold spraying, J. Therm. Spray Technol., 2006, 15(2), p 212-222

42. J. Kawakita, S. Kuroda, T. Fukushima, H. Katanoda, K. Matsuo and H. Fukanuma, Dense titanium coatings by modified HVOF spraying, Surf Coat Technol., 2006, 201, p 1250-1255

43. J. Kawakita, H. Katanoda, M. Watanabe, K. Yokoyama and S. Kuroda, Warm spraying: An improved spray process to deposit novel coatings, Surf Coat Technol., 2008, 202, p 4369-4373

44. N.W. Khun, A.W.Y. Tan and E. Liu, Mechanical and tribological properties of cold-sprayed Ti coatings on Ti-6Al-4V substrates, J. Therm. Spray Technol., 2016, 25(4), p 715-724

45. D. Goldbaum, R.R. Chromik, S. Yue, E. Irissou and J.G. Legoux, Mechanical property mapping of cold sprayed Ti splats and coatings, $J$. Therm. Spray Technol., 2011, 20(3), p 486-496

46. P. Cavaliere and A. Silvello, Processing conditions affecting residual stresses and fatigue properties of cold spray deposits, Int. J. Adv. Manuf. Technol., 2015, 81(9-12), p 1857-1862

47. A.Y. Liu and M.L. Cohen, Prediction of New Low Compressibility Solids, Science, 1989, 245(4920), p 841-842

Publisher's Note Springer Nature remains neutral with regard to jurisdictional claims in published maps and institutional affiliations. 